\title{
Evaluation of Chinese Online Tourism and Travel Service Providers from the Users' Perspective
}

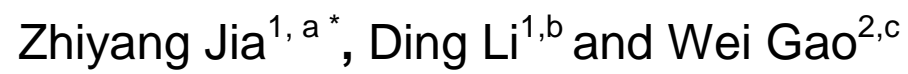 \\ ${ }^{1}$ Tourism and Culture College of Yunnan University, Lijiang, China \\ ${ }^{2}$ School of Information Science, Yunnan Normal University, Kunming, China \\ ajdyjazz@gmail.com, ${ }^{b}$ dingli.ynu@gmail.com, ${ }^{\mathrm{c}}$ gaowei@ynnu.edu.cn \\ * Corresponding author
}

Keywords: Online Tourism Service; Online Travel Service; Service Evaluation; Cyber Tourism.

\begin{abstract}
As the Internet develops faster, it has also become more useful. Many Chinese Internet users utilize online tourism and travel services for vacation and travel. To evaluate the prevalent online tourism and travel service providers, this paper selects five of the most popular providers in China, including Ctrip, Qunar, Kuxun, Taobao Travel and eLong. Five-star rating approach is adopted in the evaluation process. Some purchasing experience criteria of are summarized from the users' perspective, such as product variety, price comparison, customer reviews, customer service and mobile APP. Based on the total ratings, statistical analysis is used to explain the final results.
\end{abstract}

\section{Introduction}

Online tourism and travel service have emerged as one of the most booming industries along with the global development of e-commerce. Enormous Chinese Internet users are choosing online tourism and travel services, which are offered by the cyber providers [1]. Among the online travel service providers having their own characteristics, the author makes a real experience study on the online travel service providers, so that the users may choose the most suitable business. It is expected to carry on the comprehensive review of the online travel from the users' perspective.

According to the popularity of the tourism and travel service providers in China, researchers choose five of the most popular online travel service providers, including Ctrip [2], Qunar [3], Kuxun [4], Taobao Travel [5] and eLong [6].

Ctrip International Ltd. (Nasdaq: CTRP), founded in 1999, is headquartered in Shanghai. As a leading online travel service enterprise in China, Ctrip provides more than 40 million registered members with the comprehensive services, including hotel reservation, flight ticketing, vacation planning, corporate travel management, preferential merchant and tourism information.

Qunar, founded in 2005 and headquartered in Beijing, is the world's most popular Chinese travel platform. According to the data released by iUser-Tracker [7] in January 2013, Qunar ranked top of the travel sites with 74.74 million visits while there were more than 34 million active users in the mobile client.

Kuxun, the Chinese subsidiary of TripAdvisor [8] with a business model similar to Qunar came in a distant second, is a leading travel search engine in China as well as the subsidiary of the world's largest online travel service company Expedia. Kuxun was founded in early 2006. Based on the experiential service, Kuxun covers more than 200 domestic cities with nearly 35 million daily visits.

Taobao Travel is a comprehensive travel service platform being affiliated with Taobao. Till April 2013, Taobao Travel had more than 2400 ticket agents and travel sellers to conduct the trading services of tourism products. Except for the tickets, Taobao Travel provides the registered member with more than 30000 hotels and hostels as well as more than 170,000 entrance tickets. 
eLong, Inc. (Nasdaq: LONG) is a leading mobile and online travel service provider in China. Till January 2014, there are 20 million registered members, and the user's single PV of websites reach up to more than 10 million a month. Throughout the country, eLong has established the partnership with more than 20,000 hotels and 2,000 websites.

\section{Comprehensive Evaluation}

Five-star rating approach [9] is adopted in the evaluation. Researchers summarize six criteria in buying the online tourism products, including product variety, the user's purchasing experience, price comparison, customer reviews, customer service and mobile APP.

Since the product variety and destinations, being supported by the online travel service providers, are numerous, it is impossible to make the considerations in the detailed statistics. For this reason, the sampling approach is adopted. In the evaluation process, researchers simulate the whole process for a tourist to buy the online travel products with two of the most popular tourist attractions as the destinations. All the evaluation links are extended around the related tourism products of the two tourist attractions in showing a real experience process as an ordinary consumer.

Product Variety. The offered tourism product variety refers to the travelling means, such as cycling, tours and cruises as well as the product mixes of the domestic and foreign travel, the number of the attractions in related to the products, etc. The focused evaluation items are measured by tourism product type and quantity, the number of the available reserved hotels, the quantity of products and optional products. The rating is based on the evaluation results, as shown in Table 1.

With the product variety increase, the consumer has more choices. During the evaluation process, it is quite difficult to meet every demand of the consumers in the journey. Based on its site features and resource advantages, Taobao Travel can meet the needs of consumers to a large extent. In this way, the consumers are able to find the desired products according to the different requirements. Taobao Travel has the definite advantage in the product variety.

Table 1 Product Variety Related Ratings

\begin{tabular}{llllll}
\hline Service Provider & Flight Tickets & Hotel & Product Quantity & Product \\
Variety & Total \\
\hline Ctrip & $\star \star \star \star$ & $\star \star \star \star$ & $\star \star \star$ & $\star \star \star \star$ & 15 \\
Qunar & $\star \star \star \star \star$ & $\star \star \star \star$ & $\star \star \star \star \star$ & $\star \star \star \star$ & 18 \\
Kuxun & $\star \star \star \star$ & $\star \star \star \star \star$ & $\star \star \star \star$ & $\star \star$ & 15 \\
Taobao Travel & $\star \star$ & $\star$ & $\star \star \star$ & $\star \star \star \star$ & 10 \\
eLong & $\star \star \star \star$ & $\star \star \star \star \star$ & $\star$ & $\star$ & 11 \\
\hline
\end{tabular}

Price Comparison. It is of great importance to compare the product price, so it is necessary to evaluate the same online tourism product with the highest cost performance in terms of the different service providers.

As shown in Table 2, in terms of the product price from the overall online travel E-commerce providers, Taobao Travel creates the most affordable platform of tourism shopping based on its powerful channels of Taobao B2C platform. The platform of Taobao Travel is relatively reliable of which its third-party sites of external resources are also certified with the trustworthy reputation. Ctrip and eLong have their own independent product sales channels, but the service price is relatively high yet having the guaranteed credit and after-sales service. Thus they are preferred by the consumers in the pursuit of quality. 
Table 2 Price Comparison Ratings

\begin{tabular}{lccccc}
\hline $\begin{array}{l}\text { Service } \\
\text { Provider }\end{array}$ & Flight & Hotel & Product & Product \\
Quantity & Variety & Total \\
\hline Service & Flight & \multirow{2}{*}{ Hotel } & Product & Product \\
Provider & Tickets & Quantity & Variety & Total \\
\hline Ctrip & $\star \star \star \star$ & $\star \star \star \star$ & $\star \star \star$ & $\star \star \star \star$ & 15 \\
Qunar & $\star \star \star \star \star$ & $\star \star \star \star$ & $\star \star \star \star \star$ & $\star \star \star \star$ & 18 \\
Kuxun & $\star \star \star \star$ & $\star \star \star \star \star$ & $\star \star \star \star$ & $\star \star$ & 15 \\
Taobao Travel & $\star \star$ & $\star$ & $\star \star \star$ & $\star \star \star \star$ & 10 \\
eLong & $\star \star \star \star$ & $\star \star \star \star \star$ & $\star$ & $\star$ & 11 \\
\hline
\end{tabular}

Shopping Experience. The user's operation experience on the online shop-ping page is of great importance. During the whole process, the website operation experience for a consumer to purchase the online tourism products will be evaluated from the aesthetics of the webpage, the operation convenience and other perspectives. Product variety related ratings are made, including whether to buy the products depends on the prompt purchase process, exquisite page setup, convenient operation experience and convenient payment.

Table 3 Shopping Experience Ratings

\begin{tabular}{|c|c|c|c|c|}
\hline Service Provider & UI & Functional Experience & Payment & Total \\
\hline Ctrip & 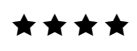 & $\star \star \star \star \star ~$ & $\star \star \star \star ~$ & 13 \\
\hline Qunar & $\star \star \star$ & $\star \star \star \star \star$ & $\star \star \star$ & 10 \\
\hline Kuxun & $\star \star \star$ & $\star \star \star$ & $\star \star \star \star \star ~$ & 10 \\
\hline Taobao Travel & $\star \star \star$ & $\star \star \star \star \star$ & $\star \star \star \star \star \star ~$ & 12 \\
\hline eLong & $\star \star \star$ & $\star \star \star \star \star ~$ & $\star \star \star$ & 11 \\
\hline
\end{tabular}

According to Table 3, ordinary tourists show more concerns over whether the most affordable price is accessible to hotel reservation, flight ticketing and tourist routes. In view of the direct reservations or search, the websites fundamentally maintain the consistent user experience of which the price is basically comparable with the similar operation process. In view of search sites, the mismatches of the displayed price and the actual purchase price are still needed to be solved. After all, the consumers have much more diverse choices at present.

Customer Reviews. Users' comments on the online products are evaluated, such as the quantity, quality, objective and fair of the customer reviews.

In terms of several sites, almost all of the featured reviews are involved with the hotels since it is essential for the tourists to find a suitable cost-effective hotel. The comments are much more specific rather than generally proposed. The comments are involved with price, sanitation, service, environment, facilities and other details. The comments are much impressive in sticking to the facts and speaking out the bad and the good. In a rare situation, the website will deliberately remove the negative comments. The quantity and quality of customer comments/reviews in the websites are assessed in Table 4.

Table 4 Customer Reviews

\begin{tabular}{lllc}
\hline Service Provider & Quantity & Quality & Total \\
\hline Ctrip & $\star \star \star \star \star$ & $\star \star \star \star \star$ & 10 \\
Qunar & $\star \star \star$ & $\star \star \star \star$ & 7 \\
Kuxun & $\star$ & $\star \star$ & 3 \\
Taobao Travel & $\star \star \star \star \star$ & $\star \star \star \star$ & 9 \\
eLong & $\star \star \star \star \star$ & $\star \star \star \star \star$ & 10 \\
\hline
\end{tabular}


Customer Service. In order to evaluate the attitude of the after-sales customer service, some consulting questions are determined. As shown in Table 5, some customer service related scenarios, such as requiring the pickup service from the sites and delivering the complaints if the compulsive shopping action appeared or the accidents occurred in the process are performed.

In general, there are the abundant of customer services for every website. It is quite rare for customer service to connect the phone for a long time. The attitude is also very good in giving the accurate reply according to the basic requirements. However, the customer service for some sites cannot cover all of the business. The call centers of Ctrip and eLong are accessible to offer the booking service, but the customer service of other sites can only deal with the consulting issues, complaints and the similar issues.

Table 5 Customer Service Ratings

\begin{tabular}{llllc}
\hline Service Provider & Response Time & Service Attitude & Details & Total \\
\hline Ctrip & $\star \star \star \star$ & $\star \star \star \star \star$ & $\star \star \star \star$ & 15 \\
Qunar & $\star \star \star \star$ & $\star \star \star \star$ & $\star \star \star \star$ & 12 \\
Kuxun & $\star \star \star$ & $\star \star \star \star$ & $\star \star \star \star$ & 11 \\
Taobao Travel & $\star \star \star \star$ & $\star \star$ & $\star \star \star$ & 9 \\
eLong & $\star \star \star \star \star$ & $\star \star \star \star \star$ & $\star \star \star \star$ & 14 \\
\hline
\end{tabular}

Mobile APP. It is mainly considered to study the mobile APP [10] of each website in conducting the comprehensive evaluations (as shown in Table 6) from the user-friendly user APP interface, the abundant functions of APP program, the performance of APP (the compatibility with operating system of mobile phone, the start-up speed of the software, the running stability of the software, etc.).

With the popularity of smart phones, all the travel service sites have developed their own APP, and its functions are not limited to the information query of the destination and tourist attractions, photos sharing, travel plans, hotel reservation, flight ticketing and train ticketing and other basic functions. In terms of the functions, Ctrip and Qunar have provided more abundant and practical APP.

Table 6. Mobile App Ratings

\begin{tabular}{llllc}
\hline Service Provider & User-friendly & Function & Performance & Total \\
\hline Ctrip & $\star \star \star \star$ & $\star \star \star \star$ & $\star \star \star$ & 13 \\
Qunar & $\star \star \star \star$ & $\star \star \star \star \star$ & $\star \star \star \star$ & 13 \\
Kuxun & $\star \star \star \star$ & $\star \star \star \star$ & $\star \star \star \star$ & 12 \\
Taobao Travel & $\star \star \star \star$ & $\star \star \star$ & $\star \star \star \star \star$ & 12 \\
eLong & $\star \star \star$ & $\star \star \star$ & $\star \star$ & 8 \\
\hline
\end{tabular}

\section{Summary}

Researchers have summarized all the rating results of the six criteria in buying the online tourism products, in order to make the evaluations on the user experience in Table 7. 
Table 7 Summary of All the Ratings

\begin{tabular}{|c|c|c|c|c|c|c|c|}
\hline $\begin{array}{l}\text { Service } \\
\text { Provide } \\
\mathrm{r}\end{array}$ & $\begin{array}{l}\text { Product } \\
\text { Variety }\end{array}$ & Price & $\begin{array}{l}\text { Shopping } \\
\text { Experience }\end{array}$ & Reviews & $\begin{array}{l}\text { Customer } \\
\text { Service }\end{array}$ & Mobile App & Total \\
\hline Ctrip & 15 & 13 & 13 & 10 & 15 & 13 & 79 \\
\hline Qunar & 18 & 15 & 10 & 7 & 12 & 13 & 75 \\
\hline Kuxun & 15 & 11 & 10 & 3 & 11 & 12 & 62 \\
\hline $\begin{array}{l}\text { Service } \\
\text { Provide } \\
\mathrm{r}\end{array}$ & $\begin{array}{l}\text { Product } \\
\text { Variety }\end{array}$ & Price & $\begin{array}{l}\text { Shopping } \\
\text { Experience }\end{array}$ & Reviews & $\begin{array}{l}\text { Customer } \\
\text { Service }\end{array}$ & Mobile App & Total \\
\hline $\begin{array}{l}\text { Taobao } \\
\text { Travel }\end{array}$ & 10 & 12 & 12 & 9 & 9 & 12 & 64 \\
\hline eLong & 11 & 10 & 11 & 10 & 14 & 8 & 64 \\
\hline
\end{tabular}

Due to the strong product channels and high service quality, Ctrip (79 stars) has won the first place of the user evaluation activities and Ctrip is preferred by the business users. Although it is very similar to the Ctrip, eLong gets less stars (64 stars), which can be inferred from the amount of page visits. Based on its powerful Taobao sales platform, Taobao Travel $(64$ stars $)$ wins the title of the most cost-effective online travel service provider in constructing the most cost-effective travel tourism product sales platform. Qunar (75 stars) and Kuxun (62 starts) are the most popular search engines, and they have the good performance in providing the users with the comprehensive tourism product information. As to the above analysis, online tourism and travel service providers have gradually improved their websites from the perspective of the user experience and customer service.

\section{Acknowledgment}

The research work was supported by National Natural Science Foundation of China under Grant No. 11401519, Natural Science Foundation of Yunnan Provincial education department under Grant No. 2012Z143C and scientific research foundation of the Lijiang Municipal Science and Technology Bureau under Grant No. ljs2013-09.

\section{References}

[1] Shuxia Dong, and Yi Zhou, Analysis of the B2C Online Travel in China: Using Mangocity.com as an Example. Proc. of 2013 Int. Conf. on Computer Sciences and Application, IEEE, Wuhan, pp. 110-113, 2013.

[2] Ye, Qiang, Rob Law, and Bin Gu, The Impact of Online User Reviews on Hotel Room Sales. International Journal of Hospitality Management, 28(1), pp. 180-182, 2009.

[3] Kuang, Hongyun, and Xuehui Zeng. Research on the Development of Tourism Electronic Commerce in China-A Case Study of Website Qunar and Uzai. Proc. of the 5th Int. Conf. on Innovation Management and Industrial Engineering, IEEE, Sanya, pp. 316-319, 2012.

[4] Jiang, Lin, et al. Strategy Transition and Marketing innovation of a Vertical Search Engine: The case of Kuxun company. Frontiers of Business Research in China, 5(4), pp. 619-634, 2011.

[5] Ding, Researchers i. Challenges and Opportunities of Hotel oOnline Booking in China. Lecture Notes in Computer Science, Vol. 6770, pp. 3-12, 2011.

[6] Yuan Hui, Xu Researchers i, and Yang Chengfu. A User Behavior-based Ticket Sales Prediction Using Data Mining Tools: An Empirical Study in an OTA Company. Proc. of the 11th Int. Conf. on Service Systems and Service Management, IEEE, Beijing, pp. 1-6, 2014.

[7] Guihong, $\mathrm{Xu}$, and Xiao Liang. On the Problem and Countermeasure of Network Financial Service Development of China. Proc. Of the 2010 Int. Conf. on E-Business and E-Government, IEEE, Guangzhou, pp. 2073-2075, 2010.

[8] Peter O'Connor. Information and Communication Technologies in Tourism, Springer-Verlag: Wien, pp. 47-58, 2008. 
[9] Olson, Eric M., Stanley F. Slater, and G. Tomas M. Hult. The Importance of Structure and Process to Strategy Implementation. Business Horizons, 48(1), pp. 47-54, 2005.

[10]Feng Tian, Feifei Xu, Jiacai Fu. Augmented Reality Technology Overview for Tourism App Development. Proc. of the 12th Int. Conf. on Machine Learning and Cybernetics, IEEE, Tianjin, pp. 14-17, 2013. 